Hamlin, R. G., \& Patel, T. (2020) Toward an emergent Asian behavioural model of perceived managerial and leadership effectiveness: a cross-nation comparative analysis of effective and ineffective managerial behaviour of private sector managers in India and South Korea. Human Resource Development International, 31(?), https://doi.org/10.1080/13678868.2019.1700076

Toward an Emergent Asian Behavioural Model of Perceived Managerial and Leadership Effectiveness: A cross-nation comparative analysis of effective and ineffective managerial behaviour of private sector managers in India and South Korea

\author{
Robert G. Hamlin, PhD \\ University of Wolverhampton, UK \\ Email: r.g.hamlin@wlv.ac.uk
}

Taran Patel, $\mathrm{PhD}$

Grenoble Ecole de Management, UniGren Alpes ComUE, France

Email: taran.patel@grenoble-em.com 


\begin{abstract}
This Type 4 (emic-and-etic) indigenous cross-case/cross-nation comparative study compares the results of two Type 3 (emic-as-emic) indigenous replication managerial behaviour studies of effective and ineffective managerial behaviour carried out within private companies in India and South Korea respectively. The method used was 'realist qualitative content analysis' (Madill, Jordon, and Shirley, 2000) involving inductive open and axial coding. Of the Indian findings $100 \%$ were found to be convergent in meaning with $94.43 \%$ of the equivalent South Korean findings. This has led to the identification of an emergent two-factor emergent Asian behavioural model of perceived managerial and leadership effectiveness comprised of 16 positive (effective) and 6 negative (ineffective) generic behavioural criteria. These criteria could be used in both countries to critically review and improve extant, or develop new, competency-based management/leadership development programmes. The research findings lend no support to claims that national culture has a major impact on managerial and leadership practices, styles and effectiveness.
\end{abstract}

Keywords: Managerial and leadership effectiveness; perceptions; behavioural model; comparative analysis; cross-case; cross-nation. 


\section{Toward an Emergent Asian Behavioural Model of Perceived Managerial and Leadership Effectiveness: A cross-nation comparative analysis of effective and ineffective managerial behaviour of private sector managers in India and South Korea}

\section{Introduction}

Most explorations of management and leadership in Asia-Pacific countries including India and South Korea have been 'normal science' (Kuhn, 1996) survey-based studies informed by theories and models of which most were developed in the U.S. (see Leung, 2007; Leung and White, 2004; Li, 2012; Tsui, 2006; Wang, 2011; Yukl, 2012). Many of these studies have been about testing the relevance and utility of particular U.S. derived models (e.g. leadership styles; transformational leadership) in various cultures, and have made little contribution to finding specific management or leadership models for non-Western cultures (Hwang, et al., 2015; Park, Han, Hwang and Park, 2019). Indeed, as Hwang et al. (2015) note, drawing upon Dickson, Den Hartog and Mitcheslson (2003), few non-Western leadership models have been derived. Furthermore, to our knowledge, few (if any) extant indigenous Asia-Pacific models of management have been developed.

These observations are supported by Panda and Gupta (2007) who claim management scholars in India: i) engage primarily in replication/imitation studies based on Western theories, models, and concepts using positivist/quantitative approaches and methods; and ii) address research problems derived mainly from reviews of extant Western literature. Although such studies do find some relevance to the Indian context, various writers argue there is a need to study research phenomena within specific [national] contexts with the help of context-relevant constructs (Budwar and Sparrow, 2002). This view is supported by Khatri et al. (2012) who argue that Indian management research and scholarship should develop cutting-edge knowledge, methods, and indigenous theories to: i) serve Indian management students better; ii) provide Indian practitioners with more effective solutions to the problems they encounter; and iii) to support the rapidly emerging community of management related scholars in India. Budwar and Sparrow's view is also supported by Rawat and Lyndon (2016) who assert that the uncritical adaption of techniques developed in Western settings may not be effective in the Indian cultural environment. Indeed, according to Pellegrini, Scandura and Jayaraman (2010) the concept of 'paternalistic leadership', which first emerged from indigenous research in China, is prevalent in many non-Western business organizations including those in India and has been shown to be positively related to employee job 
satisfaction and commitment. Furthermore, Rawat and Lyndon (2016) have found that paternalistic styles of leadership lead to subordinates' trust in their managers.

Similarly within Confucian Asian countries where most researchers conduct management and leadership studies using theories or models derived in Western cultural contexts (Dorfman, et al., 1997; Shin and Zhou, 2003), as previously mentioned, numerous scholars have argued that the findings of such studies may not be applicable to non-Western countries (Li, 2012; Liden and Antonakis, 2009). As Tsui (2007) contends, they may fail to provide insights and understanding of novel contexts or reveal indigenous aspects of management and leadership. Thus, there have been increasing calls for indigenous research to address problems identified from local (nation-specific) management/leadership-related phenomena (see Li, Zhou, and Sekiguchi, 2014; Lyles, 2009; Wolfgramm, Spiller, and Voyageur, 2014).

In response to these various calls, and as part of a cumulative series of emic replication managerial behaviour studies within private and public sector organizations in Western and non-Western countries, the authors have examined the behavioural effectiveness of managers as observed, perceived, and judged by managers and non-managerial employees within private companies in India (Hamlin, Patel., \& Patel, 2016) and South Korea (Hamlin, Kim, Chai, and Kim, 2016; Chai, Jeong, Kim, Kim, and Hamlin, 2016) respectively. Due to significant differences in the cultural values of these two Asia-Pacific countries, as reflected in the findings of Hofstede, Hofstede and Minkov (2010), it is widely assumed that people's perceptions of what behaviourally distinguishes effective managers from ineffective managers may vary across culturally diverse nations (see Park et al., 2019). However, we suggest this assertion needs to be demonstrated empirically because, as Hwang, et al. (2005) claim, very few studies have examined leadership across Confucian Asian countries. To our knowledge there have been no comparative managerial behaviour studies across the wider Asia-Pacific Region. Our study specifically addresses this research gap.

\section{Purpose of the study}

In light of the dearth of qualitative cross-case/cross-nation comparative managerial behaviour research in the Asia-Pacific Region, the purpose of this study is to compare and contrast the findings of the two aforementioned indigenous emic replication managerial behaviour studies in India and South Korea to: (i) search for similarities and differences; (ii) differentiate any identified nation-specific behavioural effectiveness indicators from those that are relevant to 
both countries and thus are nation-general; and (iii) from the nation-general findings deduce (if possible) generic behavioural effectiveness indicators that might point toward an emergent Asian behavioural taxonomy or model of perceived managerial and leadership effectiveness.

We first provide a literature review of 'indigenous management research in AsiaPacific countries' and of 'national culture and managerial/leadership effectiveness'. This is followed by an outline of the theoretical background and research questions addressed. We then describe the adopted research methods, summarize the results, discuss the implications and limitations, and close with suggested directions for future research.

\section{Literature review}

At this juncture readers should note that consistent with our earlier empirical source studies, we follow Yukl (1989) by making no distinction between 'management' and 'leadership'. Thus, our use of the term 'managerial behaviour' embraces both 'manager behaviour' and 'leader behaviour'. Additionally, our use of the word 'leadership' in the term perceived managerial and leadership effectiveness refers to the everyday supervisory leadership performed by managers at all levels of management (House and Aditya, 1997), and not to House, Hanges, Javidan, Dorfman, and Gupta's (2004) concept of strategic leadership additionally performed by organizational leaders, general managers and other members of top management teams.

\section{Indigenous management research in Asia-Pacific countries}

Within the field of management studies there is no widely accepted definition of what is 'indigenous research'. Tsui (2007) defines it as any single country study that is nationspecific. She argues such studies can either include aspects of the national context as part of the theory and methods, or alternatively researchers can take for granted the national context which she asserts is the case for studies conducted in the U.S. Other researchers claim it is the study of a unique local phenomenon from a local native-emic perspective (Lyles, 2009; Li 2012), or context-specific explorations of local phenomena that may have global implications (Li et al., 2014).

A 'four-stage' typology of indigenous research, based on the thinking of Lyles (2009) and Li, Leung, Chen and Luo (2012), has been offered by Hamlin, Kim, Chai, Kim and Jeong (2016) as follows: Type 1 (emic-as-etic with mostly Western content). This is the most basic and most common approach, and involves a naïve/uncritical application of extant theories from the West in a local context. Type 2 (etic-to-emic with imbalanced Western-Eastern content). This is a more advanced approach involving a cross-cultural comparative 
component with the potential to discover one or more novel constructs unique to the local phenomenon. Type 3 (emic-as-emic with mostly Eastern content). This is an innovative approach involving the identification and development of novel local constructs to explain local phenomena. Two examples are: Choi, Yoon, and Jeung's (2012) study in Korea that inductively derived two sets of leadership competencies at the executive and manager levels using the Delphi method; and Wang's (2011) study of managerial effectiveness within a Chinese (profit-like) organization which replicated Anon 1's managerial behaviour research within the UK. Type 4 (emic-and-etic integration with well-balanced local-global or EasternWestern content). This is the most advanced approach involving an integration of the emic theories resulting from Type 2 and Type 3 studies carried out in different local/cultural contexts, whether at the organizational, sectoral, or national level of context, with the aim of building cross-cultural constructs and theories, and thereby develop geocentric (emic-andetic) knowledge. A within-country example is Cheng's (1995) attempt to build an indigenous theory of 'paternalistic authority and leadership' based on Confucianism through a series of emic qualitative studies in Taiwan. A cross-countries example is that of Patel and Hamlin. (2012) who carried out a multiple cross-case/cross-nation comparative analysis of findings obtained from six emic replication managerial behaviour studies carried out in Germany, Romania, and the UK. This latter study resulted in the development of an emergent behavioural taxonomy of effective and ineffective managerial behaviour. Our present study is also a Type 4 (emic-and-etic) indigenous research inquiry, but in the Asia-Pacific Region.

\section{National culture and managerial and leadership effectiveness}

National culture is commonly cited in the literature as having an impact on management practices, styles, and effectiveness, not least in Asia-Pacific countries including India (Sinha, 1994 as cited in Pellegrini, Scandura and Jayaraman, 2010) and South Korea (Self, Self and Bell-Haynes, 2011). Indeed, it has been widely claimed that leadership as a concept is culturally dependent, and that leadership effectiveness is contingent upon the national culture of leaders and of their followers being similar (Brodbeck et al, 2000; Zhu, 2007). Hwang et al. (2015) have examined how different types (styles) of leadership behaviour influence the perceived job performance and thus effectiveness of managers in four Confucian Asian countries. They found 'charismatic', 'directive', and 'supportive' leadership behaviour showed a positive impact in South Korea, but 'participative' leadership behaviour was not significantly related to the effective performance of managers. Park et al. (2019) have also examined the same four 'leadership styles' in South Korea. Although most of their findings 
support Hwang et al. (2015), they found 'directive' leadership behaviour had a negative influence on team outcomes and cohesiveness.

Hofstede's (1980; 2003) framework for assessing various types of cultural attributes and values is one of the most widely used and cited approaches to help managers understand differences between national cultures, and thereby help them select a management or leadership style that is most likely to be effective in a given national and organizational context. In his research, Hofstede found that managers and employees vary on six dimensions of national culture: i) power distance- PD; ii) individualism-IDV; iii) masculinity- MAS; iv) uncertainty avoidance-UAI; v) long-term orientation-LTO; and indulgence-IND. The PD, IDV and UAI dimensions are the ones that can impact most directly on management and leadership styles. According to Hofstede, Hofstede and Minkov (2010), there are significant differences between the national culture of India and South Korea, as indicated by the scores against each of the six cultural dimensions shown in Table 1. The high PD score of 77 for

\section{INSERT Table 1 ABOUT HERE}

India is indicative of an appreciation for hierarchy and a top-down structure in society, and for organizational environments where authoritarian management is considered superior to participative management (Kazi, 2009). Similarly, the relatively high PD score of 60 for South Korea supports Fukuyama's (1995) claim that "Korean businesses tend to be run in a hierarchical, authoritarian, and centralized manner" (p. 134), and also supports Self et al.'s (2011) assertion that "Korean business leaders tend to follow a directive leadership style" ( p.44). The very low IDV score of 18 for South Korea indicates a 'collectivist culture' manifested by a close long-term commitment to others in a group (such as a family, extended family, or other extended relationship) and by strong relationships where everyone takes responsibility for fellow members of the group (Self et al., 2011). In organizational contexts this type of culture leads to managerial paternalism as "symbolized by top-heavy structures and processes, and roles designed to serve certain organizational goals as prescribed by the head of the organization" (Kazi, 2012, p. 4).

However, the validity of the concept of national culture has been questioned by Usunier (1998). As Patel (2005, 2007a, 2007b) has pointed out, cultural similarities can exist across nations and differences can exist within nations. These conflicting views bring into question claims that the process of managing employees effectively is contingent upon the national culture of managers and their employees. The present study attempts to generate new insights within the Asia-Pacific context that might make a contribution to current debate on this issue. 


\section{Theoretical background and research questions}

The two theories that guided our empirical source studies, and likewise have guided our study, are the 'multiple-constituency (MC) model of organizational effectiveness' and 'implicit leadership theory (ILT)'. Tsui (1984) has demonstrated empirically that a multiple constituency framework can be used to measure managerial effectiveness. She argues managers are perceived as operating within a social structure consisting of multiple constituencies or stakeholders (e.g. superiors, peers, and subordinates), each of whom has his or her own expectations of managers and reactions to them (Tsui, 1990). How managers are behaviourally perceived and judged by their constituencies determines their reputation for being either effective or ineffective. As Tsui and Ashford (1994) contend, good or bad perceptions of a manager's reputational effectiveness can cause subordinates to follow or ignore the leadership; and they can cause superiors and peers to give or withhold important resources such as information and co-operation.

We suggest the criteria used by individuals to make judgments about the behavioural effectiveness of managers are inevitably influenced by their unconscious, personally held, implicit leadership theories (ILTs). These ILTs consist of beliefs, convictions, and assumptions about the managerial attributes and behaviours that distinguish effective from ineffective managers (Eden and Leviatan, 1975). They can best be understood as 'cognitive prototypes' (Phillips and Lord, 1981). The better the fit between an individual's cognitive prototype and what he or she observes, the more likely it is the observed manager will be perceived and judged effective, or conversely ineffective (Foti and Luch, 1992).

The researchers of the two empirical source studies from which we obtained our empirical data adopted a multiple-constituency approach for exploring the issue of perceived managerial and leadership effectiveness. Thus, their respective samples of research participants were comprised of the superiors, peers, and subordinates of managers whose perceptions of effective and ineffective managerial behaviour were most likely influenced by their respective personally held ILTs. Our study is likewise focused on perceptions of the behavioural effectiveness of managers.

The research questions that we addressed were as follows:

RQ1. To what extent are behavioural categories of effective and ineffective managerial behaviour identified within the Indian private sector similar or different from equivalent behavioural categories identified within the South Korean private sector?

RQ2. Which of the behavioural categories from both studies are nation-specific and which are nation-general? 
RQ3. Can the behavioural categories found to be convergent in meaning across the two studies (if any) be integrated inductively and expressed in the form of an emergent Asian behavioural taxonomy or model of perceived managerial and leadership effectiveness?

\section{Research methodology and methods}

We adopted a philosophical stance based on pragmatism and the 'pragmatic approach' (Morgan 2007) which allows researchers to adopt paradigmatic assumptions that best fit the research purpose and questions (Cunliffe, 2011); and we assumed a post-positivist ontology and a constructivist-interpretivist epistemology (Guba and Lincoln 1994; Ponterotto 2005). In so doing we operated according to Tsang and Kwan's (1999) notion of empirical generalization replication, and to Berry's (1989) derived etic approach to applied research based on 'replication logic' and 'multiple cross-case analysis' (Davies, 2006; Eisenhardt, 1989). Adopting Tsui's (2007) definition of indigenous research, we addressed our three research questions by conducting a Type 4 (emic-and-etic) comparative analysis of our empirical source data obtained from the two Type 3 (emic-as-emic) managerial behaviour studies carried out respectively by Hamlin, Patel and Patel (2016) in India and Hamlin et al. (2016) in South Korea.

\section{Empirical source data used for the present study}

The empirical source data was comprised of the respective sets of positive (effective) and negative (ineffective) managerial behaviour findings that had resulted from the two Type 3 (emic-as-emic) studies cited above. The researchers of these Indian and South Korean replication studies used Flanagan's (1954) critical incident technique (CIT) to collect concrete examples (critical incidents-CIs) of effective and ineffective managerial behaviour from samples of research participants comprised of a mix of managers and non-managerial employees. In the case of the Indian study the collaborating organization was a U.S. owned subsidiary that manufactured property management software for its American parent company. The CIT data were collected from 35 research participants of whom 2 were directors, 7 senior managers, 23 middle or first-line managers, and 3 were non managerial employees. Of the 32 directors/managers, 30 were male and 2 were female with ages ranging from 26 to 54 years. Of the 3 non managerial employees, 2 were male and 1 was female with ages ranging from 25 to 35 years. In the case of the South Korean study, the sample was comprised of 45 research participants obtained from 14 of the country's 100 best companies (KFTC, 2012). These included 10 executives, 9 senior managers, 12 managers, and 14 nonmanagerial employees. Of these, 25 were males and 20 females aged from 26 to 53. 
In both studies the collected CIs were subjected to open and axial coding (Flick, 2014) to classify and group them into discrete behavioural categories. Each category was then interpreted and labelled with a behavioural statement (BS) describing in essence the meaning held in common with all of its constituent CIs. To ensure trustworthiness of the findings, the respective researchers engaged in 'member-checking' during and immediately following the CIT interviewing. In the Indian study the CIT data were collected in the English language because all the Indian research participants were bi-lingual. In the case of the South Korean study, all the CIT data were collected in the Korean language by the four of five coresearchers who were native South Koreans. The data were then translated into English involving an iterative 'back-and-forth' translation process with bilingual native English speakers. At the data analysis stage of both studies, a form of investigator triangulation (Easterby-Smith, Thorpe and Lowe, 1991) was used to ensure internal validity (credibility) and reliability (dependability). The translated CIs were first analysed independently by the researchers of each study, and then jointly to arrive at a consensus regarding their respective deduced BS data sets.

\section{Research methods used for the present study}

As previously mentioned, the empirical source data and unit of analysis used for this comparative study were the deduced BS data sets obtained from the aforementioned Indian and South Korean CIT replication managerial behaviour studies.

Data analysis. Author 1 subjected the Indian and South Korean positive and negative BSs to 'realist qualitative analysis' (Madill, Jordon, and Shirley, 2000). This involved inductive open coding to identify the salient unit of meaning (concept/code), and then axial coding to search for evidence of sameness, similarity, or congruence of meaning (Flick, 2014). Following the example of Hamlin et al. (2016, p. 249) "Sameness was deemed to exist when the sentences or phrases used to describe two or more BSs were identical or near identical. Similarity was deemed to exist when the BS sentences and/or phrases were different, but the kind of meaning was the same. Congruence existed where there was an element of sameness or similarity in the meaning of certain phrases and/or key words". Where convergences of meaning were found the respective Indian and South Korean BSs were accordingly grouped, juxtaposed against each other, and integrated into a number of behavioural categories comprised of both Indian and South Korean BSs. Each deduced behavioural category was interpreted and labelled with a statement (behavioural indicator-BI) describing in essence the composite meaning of the category. The so derived negative BIs and underpinning BSs were further analysed to identify those that described an absence of the 
types of managerial behaviour indicative of one or more of the derived positive BIs. These respective 'near opposite' negative and corresponding positive BIs were juxtaposed against each other and deemed to belong to the same behavioural construct comprised of indicative effective and ineffective managerial behaviours..

Trustworthiness of the findings. A form of investigator triangulation (Easterby-Smith, Thorpe, and Lowe, 1991) was deployed to ensure internal validity (credibility) and reliability (dependability) of the findings. Specifically, the results of the comparative analyses conducted independently by Author 1 were sent to Author 2 for her independent code crosschecking (Gibbs, 2007). Where discrepancies arose between their respective interpretations these were reconciled through critical examination and discussion. Their agreed analyses were then sent for code cross-checking to a confirmatory auditor. Where he was unable to confirm the coding, categorization and classification of certain BIs and underpinning BSs, these were returned and iteratively re-elaborated until agreement was reached. Issues of plausibility (confirmability) and external validity (transferability) were addressed through our use of multiple data sources and mutual validation through the comparative cross-case/crossnation processes.

\section{Results}

The qualitative content analysis (open and axial coding) of the BSs ( $\mathrm{n}=58$ ) obtained from the Indian emic replication study against the BSs $(n=104)$ obtained from the equivalent South Korean private sector-related replication study revealed high degrees of convergence. Sixteen positive behavioural categories/indicators (BIs) of perceived managerial and leadership effectiveness were identified as presented in Table 2. Eleven negative BIs were identified as listed in Table 3. As can be seen in both tables, for each behavioural category the respective

\section{INSERT Table 2 and Table 3 ABOUT HERE}

descriptive BI label has been numbered and typed in bold; and below it can be seen the juxtaposed Indian and South Korean BSs constituting that category. As can also be seen, $100 \%(n=37)$ of the Indian positive BSs contain a facet of meaning that is either the same as, or similar to, or has an element of convergent meaning with $94.43 \%(n=50)$ of the juxtaposed South Korean positive BSs. Similarly, 100\% $(n=21)$ of the Indian negative BSs contain a facet of meaning that is either the same as, similar to, or has an element of convergent meaning with $96.08 \%(n=49)$ of the juxtaposed South Korean negative BSs. Overall, just 3 of the $53(5.85 \%)$ positive and 2 of the $51(3.92 \%)$ negative South Korean BSs show no element of congruent meaning with any of the Indian BSs. 
Subsequent analysis of the descriptive labels of each derived behavioural category (BI) and its constituent BSs revealed that 5 of the 11 negative BIs (N1, N2, N3, N5 \& N9) were 'near-opposite' in meaning to various 'units of meaning' comprising one or more of 7 of the positive BIs (P1, P2, P3, P4, P9, P11 \& P12) (see Table 4). For example, the meaning of N3: 'Shows little or no empathetic support for staff and/or sensitivity for their feelings in stressful situations' [i.e. having care and concern] is very close to the meaning of P11: 'Takes a personal interest in and shows care and concern for staff and their well-being' [i.e. in stressful or difficult situations]. Two other negative BIs (N4 \& N11) contain 'units of

\section{INSERT Table 4 ABOUT HERE}

meaning' that are 'near- opposite' in meaning to some or all of the 'units of meaning' constituting two other positive BIs (P15 \& P16), as also indicated and illustrated in Table 4. For example, the two 'units of meaning' typed in italics in N4: 'Exhibits mistrustful, nonlistening, non-consultative controlling autocratic behaviour' describe acts that are opposite to those described in P15: 'Listens to staff ideas/opinions and involves them in decisionmaking'. Most of the 'units of meaning' contained within these seven negative BIs are descriptions of managerial 'acts of omission' indicating the absence of the types of behaviour represented by various units of meaning of the corresponding positive BIs. In contrast, the negative BIs (N6, N7, N8, \& N10), elements (certain 'units of meaning') of negative BIs (N4 $\&$ N11), describe 'acts of commission' of the kind associated with least effective and ineffective managers.

\section{Discussion}

The most significant finding of our study is that the research participants of the Indian private sector-related study perceived the effective and ineffective managerial behaviours manifested by managers within their own organization in much the same way, and in similar terms, as managers and non-managerial employees within private companies in South Korea. That $100 \%$ of the Indian BSs and $95.20 \%$ of the South Korean BSs are convergent in meaning, suggest that national culture has little impact on determining what behaviourally differentiates effective managers from ineffective managers in those two countries. According to Hofstede, in countries such as India and South Korea where the respective scores on the power distance dimension are high, employees will prefer authoritarian management to participative management. But such leadership styles are contrary to what our research suggests is required if managers are to be perceived effective. Mistrusting, non-listening, nonconsultative, and controlling autocratic behaviours are identified with ineffective managers; whilst in sharp contrast, listening to staff ideas and opinions and involving them in decision 
making is associated with being an effective manager. This finding presents a challenge to Hwang et al (2015) who claim 'participative' leadership behaviour is not significantly related to effective managerial performance in South Korea. Furthermore, our findings support Park et al. (2019) who claim 'directive' leadership behaviour such as autocratic, coercive and controlling leadership styles have a negative influence on team outcomes and cohesiveness, and are thus identified with ineffective managerial performance.

According to Hofstede, in highly 'collectivist' and 'long term oriented' cultures such as South Korea, people are likely to appreciate authoritarian and paternalistic managers who adopt not only autocratic (controlling) leadership styles, but also benevolent leadership styles that focus on looking after the well-being of employees. However, as can be seen in Table 2, 'taking a personal interest in and showing care and concern for staff and their well-being' is also valued by private sector managers and non-managerial employees in India where the national culture is much more individualistic and much less long term oriented than in South Korea.

The above findings suggest the behavioural statements (BSs) of perceived managerial and leadership effectiveness obtained from the two Type 3 (emic-as-emic) indigenous studies of managerial behaviour observed in Indian and South Korean private companies respectively, and used as empirical source data for our comparative study, are not nationspecific. Rather, within the Asia-Pacific Region, they appear mostly to be nation-general. Indeed, the high degrees of empirical generalization as to what behaviourally differentiates effective Indian managers from ineffective ones, against what has been found in South Korea, pose a challenge to predominant discourse which asserts that managerial behaviour is contingent upon the cultural specificities of particular countries and societies (House et al, 2004, Wendt, Euwema, and Emmerik, 2009). Thus, our findings bring into question the validity of past claims that national culture has a major impact on management practices, styles, and effectiveness, and on how employees perceive, judge and respond to the managerial behaviour manifested by their respective managers (Alas, Tafel, and Tuulik,, 2007; Brodbeck, et al, 2000; Morrison, 2000).

Although several researchers have demonstrated that both similarities and differences exist between the perceptions of effective leadership behaviour across different nations (Arvonen and Ekvall, 1999; Dorfman et al., 1997), our study has not revealed any differences in the case of private companies in India and South Korea. As can be deduced from Table 2 and Table 3, no nation-specific managerial behaviours surfaced in the Indian study findings; and nothing in the wording of the 3 positive and 2 negative non-convergent BSs from the 
South Korean study suggest they are context-specific, whether at the organizational, sectoral, or national/societal level.

We suggest our findings point toward the possibility of developing through empirical generalization replication research (Tsang and Kwan, 1999) an emergent two-factor Asian behavioural model of perceived managerial and leadership effectiveness comprised of 16 positive (effective) and 6 negative (ineffective) behavioural constructs that we refer to as generic behavioural criteria (GBCs) (see Table 5). These GBCs and respective underpinning INSERT Table 5 ABOUT HERE

BSs provide distinctive insights and understanding of the specific types of behaviour that managers in private sector companies in India and South Korea (and perhaps also in other Asia-Pacific countries) need to emulate or avoid if they are to be perceived and judged effective by their respective superiors, peers and subordinates. The model is distinctive by virtue of having been derived from Asia-Pacific indigenous empirical data, as well as through the processes of empirical generalization replication research. Thus, it represents a potential Eastern 'mid-range theory' of managerial and leadership behavioural effectiveness in the making, based as it is on the findings of research uninfluenced by Western theories, models, and concepts. As such, this Eastern model is likely to have much greater resonance, credibility, acceptability and impact in Asian countries than the managerial and leadership effectiveness related theories, behavioural constructs, models, frameworks and taxonomies derived from empirical research carried out solely in the U.S.A. or in other Western countries.

\section{Implications for HRD Practice}

The emergent two-factor Asian behavioural model of perceived managerial and leadership effectiveness is likely to have potential validity, relevance and transferability across other private sector companies in India and South Korea. We suggest its constituent GBCs and underpinning BSs could be used generically with some degree of confidence by HRD and other HR practitioners working in various parts of the private sector in India and South Korea to: (i) develop indigenous key performance indicators for measuring the behavioural effectiveness of managers in Indian and Korean private sector organizations; (ii) critically evaluate and revise in-use behavioural management competency frameworks and management/leadership development programmes; (iii) help managers adopt managerial and leadership styles that are in fit with the ILT prototype expectations of their superiors, peers and subordinates, and thereby manage and lead more effectively; and (iv) help foreign MNCs in India and South Korea become better prepared to recruit, assess, and develop both their indigenous and expatriate managers. Furthermore, managers themselves could also use the 
GBCs to self-evaluate their behavioural effectiveness and identify needs for selfimprovement and further personal development.

\section{Limitations and directions for future research}

We acknowledge three limitations. First, in our Indian emic replication source study only 100 negative CIs were collected compared to 205 positive CIs. This means there could be other negative BSs of perceived managerial and leadership effectiveness yet to be identified within the collaborating Indian private company. Second, only 3 of 35 participants (9\%) in the Indian study were non-managerial employees, whereas 14 of the 45 South Korean study participants (30\%) were non-managerial employees. Third, although our Indian single organization findings have been shown to be generalized to other private sector companies, these have been situated in another Asian country-South Korea. Hence, we recommend more Type 3 (emic-as-emic) indigenous replication studies should be carried out in other Indian private sector companies to further mutually validate the findings within the Indian national context. However, in these studies a much higher proportion of non-managerial employees comprising the samples of research participants needs to be secured. Building on from the current study, we suggest more Type 3 indigenous replication studies should be carried out in public and third (non-profit) sector organizations as well as in private companies within both India and South Korea. The aim should be to search for evidence of empirical generalization across all three organizational sectors. The findings from these inquiries could then be used as cases to 'test' and refine the tentative two-factor behavioural model that has emerged from the present study, and thereby develop an Asian general behavioural model of perceived managerial and leadership effectiveness

\section{Conclusion}

This paper offers new and contextually relevant insights into the types of managerial behaviours that managers within Indian and South Korean private companies need to emulate (or avoid exhibiting) if they are to be perceived as effective by their superiors, peers and subordinates. Potentially, the findings have relevance and utility for informing HRD policy and practice in many other private sector organizations in both countries, and perhaps also in other Asia-Pacific countries. We hope our work will stimulate other researchers to engage with Type 3 and Type 4 indigenous research, not only to explore the issue of managerial and leadership effectiveness but also to investigate other HRD-related and management-related issues that need to be better understood.

\section{References}

Alas, R., K. Tafel, and K. Tunlik. 2007. "Leadership Style during Transitions in Society: 
Case of Estonia." Problems and Perspectives in Management 5 (1): 50-60.

Arvonen, J., and G. Ekvall. 1999. "Effective Leadership Style: Both universal and contingent?" Creativity \& Innovation Management 8 (4): 242-257.

Berry, J. 1989. "Imposed Etics-Emics-Derived Etics: The Operationalization of a Compelling Idea." International Journal of Psychology 24: 721-735.

Brodbeck, F., M. Frese., S. Akerblom, et al. 2000. "Cultural Variation of Leadership

Prototypes Across 22 European Countries." Journal of Occupational and

Organizational Psychology 73: 1-29.

Budwar, P. S. and P. R. Sparrow. 2002. "How Business Schools Lost Their Way." Harvard Business Review 83: 73-92.

Chai, D-S., S. Jeong, J. Kim, S. Kim, and R. G. Hamlin. 2016. "Perceived managerial and leadership effectiveness in a Korean context: An indigenous qualitative study." Asia Pacific Journal of Management, 33 (3): 789-820.

Cheng, B. S. 1995. "Paternalistic Authority and Leadership: A Case of a Taiwanese CEO Bulletin of the Institute of Ethnology Academic Sinic 79: 119-171 (in Chinese).

Choi, M., H. J. Yoon and C. Jeung. 2012. "Leadership Development in Korea: A Delphi Study." Asia Pacific Journal of Human Resources 50: 23-42.

Cunliffe, A. L. 2011. Crafting Qualitative Research: Morgan and Smircich 30 Years On. Organizational Research Methods 14: 647-673.

Davies, H. 2006. "Improving the Relevance of Managerial Research: Evidence-based Management: Design Science or Both?" Business Leadership Review 3 (3): 1-6.

Dixon, M. W., D. N. Den Hartog, and J. K. Mitchelson. 2003. "Research on Leadership in a Cross-Cultural Context: Making Progress, and Raising New Questions." The Leadership Quarterly, 14 (6): 729-768.

Dorfman, P., J. Howell, Sibino, J. K. Lee, U. Tate, and A Bautista. 1997. "Leadership in Western and Asian Countries: Commonalities and Differences in Effective Leadership." The Leadership Quarterly 8 (3): 233-275.

Easterby-Smith, M., R. Thorpe and A. Lowe. 1991. Management Research: An Introduction. London, UK: Sage.

Eden, D., and U.Leviatan. 1975. "Implicit Leadership Theory as a Determinant of the Factor Structure Underlying Supervisory Behaviour Scales.” Journal of Applied Psychology 60 (6): 736-741

Eisenhardt, K.M. 1989. "Building Theories from Case Study Research.” Academy of Management Review 14: 532-550.

Flanagan, J. C. 1954. “The Critical Incident Technique.” Psychological Bulletin 51: 327-358.

Flick, U. 2014. An Introduction to Qualitative Research (5 ${ }^{\text {th }}$ Edn). London, UK: Sage.

Foti, R. J., and C. H. Luch, 1992. "The Influence of Individual Differences on the Perception and Categorization of Leaders." The Leadership Quarterly 3: 55-66.

Fukuyama, F.1995. Trust: The Social Virtues and the Creation of Prosperity. London, UK: Hamish Hamilton.

Gibbs, G. 2007. Analyzing Qualitative Data. London, UK: Sage.

Guba, E. G., and Y. S. Lincoln. 1994. "Competing Paradigms in Qualitative Research.” In Handbook of Qualitative Research, edited by N. K. Denzin and Y S. Lincoln. London, UK: Sage, 105-117.

Hamlin, R. G., S. Kim,D-S. Chai, J. Kim, J., and S Jeong. 2016. "Perceived Managerial and Leadership Effectiveness within South Korean and British Private Companies: A derived etic comparative study." Human Resource Development Quarterly 27 (2): 237-269

Hamlin, R. G., T. Patel, and C. Patel, C. 2016. "Perceived Managerial and Leadership 
Effectiveness in the Indian Private Sector: An Indigenous Qualitative Study and Comparative Analysis." Paper presented at the $17^{\text {th }}$ UFHRD International HRD Research Across Europe Conference, Manchester UK

Hofstede, G. 1980. Culture's Consequences. Beverly Hills, CA: Sage Publications.

Hofstede, G. 2003. ITIM International, Geert Hofstede Cultural Dimensions. Retrieved from www.geert-hofstede.com/hofstede dimensions.php?culture $1=95 \%$ culture $2=82$

Hofstede, G., G. J. Hofstede and M. Minkov. 2010. Cultures and Organizations: Software of the Mind ( $3^{\text {rd }}$ Edn.) New York, NY: McGraw-Hill.

House, R. J., and R. Aditya. 1997. "The Social Scientific Study of Leadership: Quo Vadis?" Journal of Management 23: 409-465.

House, R., P. Hanges, M. Javidan, P. Dorfman, and V. Gupta. 2004. Culture, Leadership and Organizations: The GLOBE Study of 62 Societies. Thousand Oaks, CA: Sage.

Hwang, S. J., L.N. Quast, B. A. Center, C-T N. Chung, H-J. Hahn, and Wohkittel, J. 2015. 'The Impact of Leadership Behaviors on Leaders' Perceived Job Performance across Cultures : Comparing the Role of Charismatic, Participative, and Supportive Leadership Behaviors in the U.S. and Four Confucian Asian Countries. Human Resource Development International, 18 (3): 259-277.

Kazi, S. 2009. Managerial Decision-Making Behavior and Impact of Culture. Tampere, Finland: Tampere University Press,.

Kazi, S. 2012. Managerial Decision-Making Style: India, Bangladesh, and Finland: Cultural side of the game." Tampere University of Applied Sciences. Retrieved on 07/03/2019 from https://core.ac.uk/download/pdf/3995388.pdf

Khatri, N., A. K. Ojha, P. Budwar, V. Srinivasan, and A. Varma. 2012. "Management Research in India: Current State and Future Directions." IIMB Management Review 24: 104-115.

Korea Fair Trade Commission (KFTC). 2012. Report for the lists of corporate groups which are restricted for mutual contribution/investment, Accessed 20 June 2014 from http://www.ftc.go.kr/news/ftc/reportView.jsp?report_data_no=4722,

Kuhn, T. S. 1996. The Structure of Scientific Revolution ( $3^{\text {rd }}$ edn.). Chicago, OH: University of Chicago Press.

Leung, K. 2007. "The Glory and Tyranny of Citation Impact: As East Asian Perspective." Academy of Management Journal 50: 510-513.

Leung, K., and S. White. 2004. Handbook of Asian Management. Boston, MA: Kluwer Academic.

Li, P. P. 2012. "Toward an Integrative Framework of Indigenous Research: The Geocentric Implications of Yin-Yang Balance." Asia Pacific Journal of Management 29: 849872.

Li. P. P., K. Leung, C. C. Chen, and J-D Luo. 2012. "Indigenous Research on Chinese Management: What and How." Management and Organization Review 8: 7-24.

Li, P. P., K. Zhou, and T. Sekiguchi. 2014. "Call for Papers: Special Issue on Indigenous Management Research in Asia." Asia Pacific Journal of Management. Available at: http://www.iacmr.org/v2en/Detail.asp?id=413

Liden, R. C., and J. Antonakis. 2009. "Considering context in psychological leadership research." Human Relations, 62: 1587-1605.

Lyles, M. 2009. Call for proposal submission for Dissertation Grant and Workshop. International Association for Chinese Management Research. Available at at: http://www.iacmr.org/Publications/MOR/IndigenousResearch/Definition of Indigenous Research MOR.pdf 
Madill, A., A. Jordon, and C. Shirley. 2000. "Objectivity and Reliability in Qualitative Analysis: Realist, Contextualist and Radical Constructionist Epistemologies." British Journal of Psychology 91: 1-20.

Morgan, B. L. 2007. "Paradigms Lost and Pragmatism Regained: Methodological Implications of Combining Qualitative and Quantitative Methods." Journal of Mixed Methods Research 1: 48-76.

Morrison, A. 2000. "Developing a Global Leadership Model." Human Resource Management $39(2 / 3): 117-131$.

Panda, A., and R. K. Gupta. 2007. "Call for Developing Indigenous Organizational Theories in India: Setting Agenda for Future." International Journal of Indian Culture and Business Management 1: 205-243.

Park, S., S. J. Han, S. J. Hwang, and C. K. Park. 2019. Comparison of Leadership Styles in Confucian Asian Countries." Human Resource Development International 22 (10): 91-100

Patel, T. 2005. Using Dynamic Cultural Theory to Explain Viability of International Strategic Alliances: A Focus on Indo-French Alliances, PhD Thesis. Milton-Keynes. U.K: Open University.

Patel, T. 2007a. "The Role of Dynamic Cultural Theories in Explaining the Viability of International Strategic Alliances: A Focus on Indo-French Alliances.” Management Decisions 45 (10): 1532-1559.

Patel, T. 2007b. Stereotypes of Intercultural Management. Delft, The Netherlands: Eburon Publishers.

Patel, T., and R. G. Hamlin. 2012. "Deducing a Taxonomy of Perceived Managerial and Leadership Effectiveness: A Comparative Study of Effective and Ineffective Managerial Behaviour Across 3 EU Countries." Human resource Development International, 15 (5): 571-587.

Pellegrini, E. K., T.A. Scandura and V. Jayaraman. 2010. “Cross-cultural Generalizability of Paternalistic Leadership: A Expansion of Leader-member Exchange." Group \& Organization Management 35 (4): 391-420.

Phillips, J.S., and R.G. Lord. 1981. "Causal Attributions and Perceptions of Leadership." Organizational Behavior and Human Performance 28: 58-83.

Ponterotto, J. 2005. "Qualitative Research in Counseling Psychology: A Primer on Research Paradigms and Philosophy of Science." Journal of Counseling Psychology 52 (2): 126-136.

Rawat, P. S., and S. Lyndon. 2016. "Effect of Paternalistic Leadership Style on Subordinate's Trust: An Indian Study. Journal of Indian Business Research 8(4): 264-277.

Self, R., D. R. Self and J. Bell-Haynes. 2011. "Intercultural Human Resource Management: South Korea and the United States." International Journal of Management \& Information Systems 15 (1): 41-48.

Shin, S. J., and J. Zhou. 2003. "Transformational Leadership, Conservation, and Creativity: Evidence from Korea." Academy of Management Journal 46: 703-714.

Sinha, J.B.P. 1994. "Major Trends in Research on Leadership and Power." Indian Psychological Abstracts and Review

Tsang, E. K. K., and K-M. Kwan. 1999. "Replication and Theory Development in Organizational Science: A Critical Realist Perspective." The Academy of Management Review 24 (4): 759-780.

Tsui, A.S. 1984. "A multiple constituency framework of managerial Effectiveness." In J. Hunt, C. Schriesheim and R. Stewart (Eds.) Leaders and Managers: International Perspectives on Managerial Behavior and Leadership. New York, NY: Pergamon. 
Tsui, A. S. 1990. "A Multiple Constituency Model of Effectiveness: An Empirical Examination at the Human Resource Subunit Level." Administrative Science Quarterly 35: 458-483.

Tsui, A. S. 2006. "Contextualization in Chinese management research.” Management and Organization Review 2: 1-13.

Tsui, A. S. 2007. "From Homogenization to Pluralism: International Management Research in the Academy and Beyond." Academy of Management Journal 50: 1353-1364.

Tsui, A. S. and S. Ashford. 1994. "Adaptive Self-Regulation: A Process View of Managerial Effectiveness." Journal of Management 20(1): 93-121

Usunier, J-C. 1998. International and Cross-cultural Management Research. London, UK: Sage

Wang, J. 2011. "Understanding Managerial Effectiveness: A Chinese Perspective." Journal of European Industrial Training 35: 6-23.

Wendt, H., M. Euwema, and I. Emmerik. 2009. "Leadership and Team Cohesiveness Across. Cultures." The Leadership Quarterly 20: 358-370.

Wolfgramm, R., C. Spiller, and C. Voyageur. 2014. "Indigenous Leadership Special Issue: Editors Commentary.” Leadership 12 (3): 263-269.

Yukl, G. A. 1989. "Managerial Leadership: A Review of Theory and Research." Journal of Management 15: 254-289.

Yukl, G. A. 2012. Leadership in Organizations. Upper Saddle River, NJ: Prentice Hall Zhu, Y. 2007). "Do Cultural Values Shape Employee Receptivity to Leadership Styles?" Academy of Management Perspectives 21 (3): 89-90.

Acknowledgment We thank Dr Carlos Ruiz at Georgia Gwinnett College, Georgia USA for acting as our confirmatory auditor. 